\title{
The art of saphenous vein grafting and patency maintenance
}

\author{
Yaron Moshkovitz, MD, ${ }^{a}$ and Ehud Raanani, $\mathrm{MD}^{\mathrm{b}}$
}

\footnotetext{
From the a Department of Cardiothoracic Surgery, Assuta Medical Center, Tel Aviv, Israel; and ${ }^{\mathrm{b}}$ Department of Cardiac Surgery, Leviev Heart Institute, Sheba Medical Center, Tel Hashomer, Israel, affiliated with the Sackler School of Medicine, Tel-Aviv University, Tel-Aviv, Israel.

Disclosures: Authors have nothing to disclose with regard to commercial support.

Received for publication Sept 2, 2015; accepted for publication Sept 2, 2015; available ahead of print Oct 7, 2015.

Address for reprints: Ehud Raanani, MD, Cardiac Surgery Department, Leviev Heart Institute, Sheba Medical Center, Tel Hashomer, Israel 52621 (E-mail: Ehud.Raanani@sheba.health.gov.il).

J Thorac Cardiovasc Surg 2016;151:300-2

$0022-5223 / \$ 36.00$

Copyright $(2016$ by The American Association for Thoracic Surgery

http://dx.doi.org/10.1016/j.jtcvs.2015.09.004
}

Coronary artery bypass grafting (CABG) surgery is usually performed in patients with multivessel coronary artery disease who need multiple grafting. ${ }^{1}$ Reports from large registries suggest that multiple arterial grafting has been used in less than $5 \%$ to $10 \%$ of patients undergoing CABG. $^{2}$ Therefore, the saphenous vein graft (SVG) still remains an essential conduit in the majority of CABG operations. The most common grafting patterns in our practice are left internal thoracic artery (ITA) to the left anterior descending artery with or without side-to-side anastomosis to a diagonal branch, right ITA in situ to the first marginal, and SVG to the posterior descending artery with or without side-to-side anastomosis to a circumflex marginal branch (Figure 1).

There is no doubt that the SVG is a great conduit for surgeons because it is usually available at the desired length, is easily harvested without being time-consuming, supplies a limitless blood flow to the myocardium, and is associated with less risk of sternal wound infection when only 1 ITA is harvested. ${ }^{3}$ On the other hand, several studies, including a recent one by Hess and colleagues, ${ }^{4}$ have shown SVG failure to be as high as $25 \%$ during the first 12 to 18 months after surgery, with late failure of approximately $50 \%$ in non-left anterior descending territories. ${ }^{5}$ Understandably, these results are of major concern because SVG failure is associated with unfavorable outcomes. ${ }^{6,7}$

The pathophysiologic mechanisms underlying SVG failure are related to the time interval after surgery: (1) Acute graft thrombosis is the main cause of acute SVG failure during the first month but may also occur later in atherosclerotic areas; (2) focal neointimal hyperplasia at anastomotic sites, in addition to thrombosis, is the underlying cause for early SVG failure occurring between 1 month and 2 years after surgery; and (3) atherosclerotic degeneration, in addition to generalized neointimal hyperplasia, is responsible for late SVG failure occurring more than 2 years after surgery. ${ }^{8}$

We believe that to achieve SVG endurance, similar to building a durable house, one should invest in both high-quality

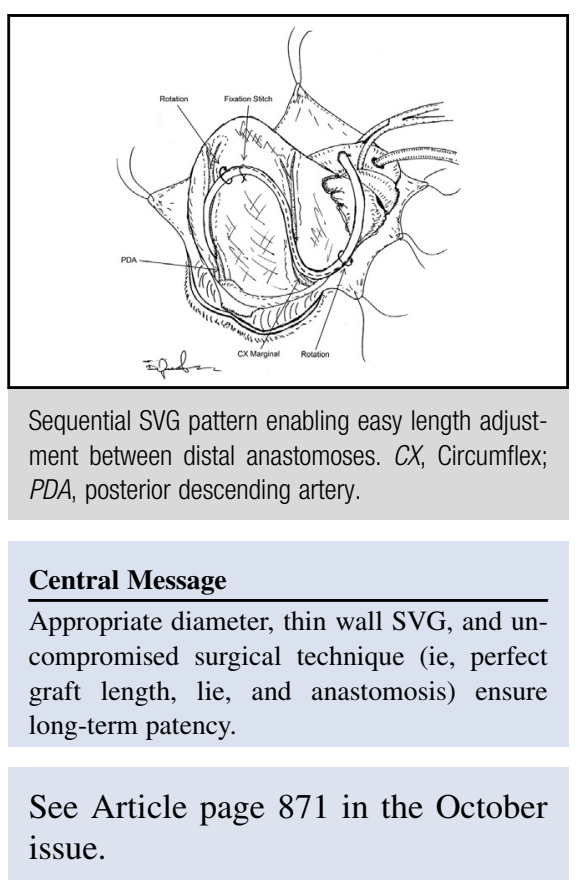

materials and reliable construction. Our hypothesis is that if properly selected, handled, and constructed, the SVG could remain patent for several decades. Furthermore, the better the initial SVG condition and surgical technique, the fewer the resources needed to maintain its patency. How does this "theory" translate into reality?

1. Surgical harvesting. High-pressure vein distension and loss of vasa vasorum continuity during SVG harvesting have been implicated as important factors facilitating SVG failure. " The "no-touch" technique, whereby SVG is harvested with perivascular fat tissue, has recently been shown to improve long-term (16 years) patency of SVG $(83 \%)$ compared with a conventional method $(64 \%)$. The SVG patency associated with the "no-touch" technique was not statistically significantly different than that of the ITA $\left(88 \%{ }^{9}\right)$ and was shown to be related to decreased early vascular smooth muscle cell activation, the basic mechanism of neointimal hyperplasia. ${ }^{10}$ However, it should be noted that although leg wound morbidity was similar at 1 year, it was still higher with the "no touch" technique compared with a conventional technique at 3 months. ${ }^{10}$

In 2005, a consensus statement of the International Society for Minimally Invasive Cardiothoracic Surgery 
endorsed the use of endoscopic vein harvesting (EVH), based mainly on its leg morbidity benefits. ${ }^{11}$ However, data regarding SVG failure are still conflicting. Although some observational studies have reported a higher rate of SVG failure and worse outcomes, ${ }^{4,12}$ with no relation to a specific EVH device, ${ }^{13}$ others have not confirmed these adverse clinical outcomes. ${ }^{14}$ However, none of these studies were specifically designed to assess the comparative safety and efficacy of EVH versus conventional harvesting. The prospective Randomized Endo-vein Graft Prospective (REGROUP) trial ${ }^{15}$ will further enlighten this controversial issue.

2. Preservation solution. In vitro and animal model data have shown that preservation solutions may influence endothelial function and SVG failure. A recent clinical study $^{16}$ showed that buffered saline solution was superior to saline and even heparinized blood in terms of 1-year SVG failure rate, with a trend toward less unfavorable clinical events at 5 years.

3. Graft implantation technique. In our practice, we prefer to harvest an SVG segment from the calf, because its diameter is smaller and its wall is thinner, thereby making it less prone to wall ischemia. Cobra-head anastomoses performed both distally and proximally under no extra tension are of utmost importance. Accurate SVG length is crucial, because both a too short and too long SVG are detrimental. ${ }^{17}$ The slightest indication of even a systolic kinking or slight tension requires readjustment. ${ }^{18}$ Several authors have reported their techniques to overcome length misjudgment. ${ }^{19,20}$ Bending an elastic tube causes tension in the greater curvature and redundancy in the lesser curvature. To avoid this structural distortion, Goor suggested performing a twist of the SVG at an appropriate degree ${ }^{18}$ : a band of $180^{\circ}$, like a U-turn, in the direction of the graft requires a graft rotation of $180^{\circ}$ (Figure 1).

Controversy still exists regarding an SVG implant to a single or sequential distal target. Data from the Project of Ex-vivo Vein Graft Engineering via Transfection (PREVENT) IV trial demonstrated higher 1-year SVG failure and trends toward worse 5-year clinical outcomes in sequential compared with single SVGs. ${ }^{21}$ However, a meta-analysis of cohort studies has shown mid- and long-term patency of sequential SVGs to be better than single SVGs. ${ }^{22}$ Because poor distal runoff is a risk factor for SVG failure, it is believed that by sequencing multiple small coronary arteries, preferably by placing the last distal anastomosis to the coronary artery with the greatest runoff, SVG flow can be maximized, thereby improving SVG patency. ${ }^{17}$ Whether SVGs are performed with single or multiple distal anastomoses, they must be technically perfect, so that the anastomoses, graft lengths, and lies are correct. ${ }^{17}$ Graft flow assessment ${ }^{23}$ could help evaluate

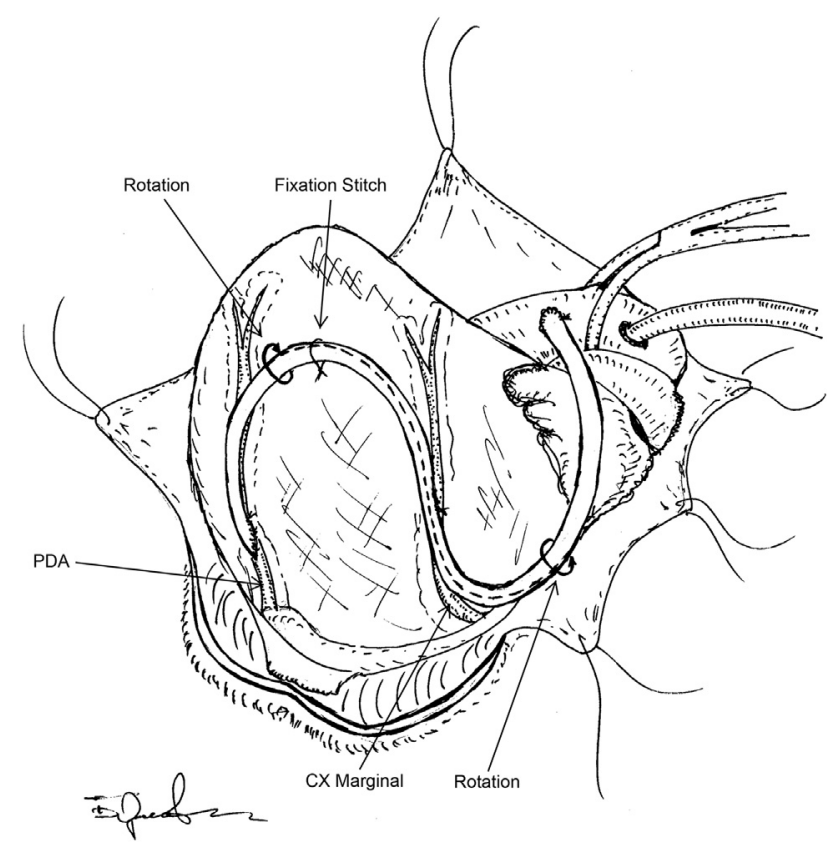

FIGURE 1. Sequential SVG pattern enabling easy length adjustment between distal anastomoses. $C X$, Circumflex; $P D A$, posterior descending artery.

anastomosis quality. Should the anastomosis be suspect, one should not hesitate to repeat it, because graft patency is the essence of CABG.

4. Medical prevention of SVG failure. Maintaining SVG patency may be enhanced by several drugs. ${ }^{8,23}$ Aspirin has been shown to demonstrate maximal impact on reducing SVG failure during the acute post-CABG stage, especially when the target vessel diameter is less than $2 \mathrm{~mm} .{ }^{24}$ The incremental benefit of dual antiplatelet therapy is questionable, because several randomized trials have shown diverging results. ${ }^{25}$ However, 2 meta-analyses of observational studies and RCTs have shown that dual antiplatelet therapy reduces early SVG failure rates, especially in off-pump CABG, but increases the risk of bleeding. ${ }^{26,27}$ Statin therapy was associated with improved graft patency in the Clopidogrel After Surgery for Coronary Artery DiseasE (CASCADE) trial. ${ }^{28}$ Smoking cessation remains a mainstay in SVG failure prevention. ${ }^{29}$

5. Future directions. Inhibition of SVG neointimal proliferation and atherosclerosis is the target of any future research aimed to prevent SVG failure. This goal can be achieved mechanically by providing external support to the SVG. External stenting reduces oscillatory shear, tends to improve lumen uniformity, and reduces intimal hyperplasia. ${ }^{30}$ However, the SVG failure rate has not been improved. ${ }^{31}$ Another potential direction is ex vivo or in situ genetic modulation. The Project of Ex-vivo Vein Graft Engineering via Transfection IV trial, ${ }^{32}$ 
which studied the effect of edifoligide, an inhibitor of transcription factor E2F responsible for upregulating several genes and believed to play a key role in the initiation of neointimal hyperplasia, has not shown any favorable effect in preventing SVG failure.

The authors thank Boris Orlov, MD, for the figure artwork.

\section{References}

1. Fihn SD, Blankenship JC, Alexander KP, Bittl JA, Byrne JG, Fletcher BJ, et al. 2014 ACC/AHA/AATS/PCNA/SCAI/STS focused update of the guideline for the diagnosis and management of patients with stable ischemic heart disease: a report of the American College of Cardiology/American Heart Association Task Force on Practice Guidelines, and The American Association for Thoracic Surgery, Preventive Cardiovascular Nurses Association, Society for Cardiovascular Angiography and Interventions, and Society of Thoracic Surgeons. J Am Coll Cardiol. 2014;64:1929-49.

2. El Bardissi AW, Aranki SF, Sheng S, O'Brien SM, Greenberg CC, Gammie JS. Trends in isolated coronary artery bypass grafting: an analysis of the Society of Thoracic Surgeons adult cardiac surgery database. J Thorac Cardiovasc Surg. 2012;143:273-81.

3. Kouchoukos NT, Wareing TH, Murphy SF, Pelate C, Marshall WG Jr. Risks of bilateral internal mammary artery bypass grafting. Ann Thorac Surg. 1990;49:210-9.

4. Hess CN, Lopes RD, Gibson CM, Hager R, Wojdyla DM, Englum BR, et al. Saphenous vein graft failure after coronary artery bypass surgery: insights from PREVENT IV. Circulation. 2014;130:1445-51.

5. Bourassa MG, Fisher LD, Campeau L, Gillespie MJ, McConney M, Lespérance J. Long-term fate of bypass grafts: the Coronary Artery Surgery Study (CASS) and Montreal Heart Institute experiences. Circulation. 1985;72: V71-8. Review.

6. Lopes RD, Mehta RH, Hafley GE, Williams JB, Mack MJ, Peterson ED, et al. Relationship between vein graft failure and subsequent clinical outcomes after coronary artery bypass surgery. Project of Ex Vivo Vein Graft Engineering via Transfection IV (PREVENT IV) Investigators. Circulation. 2012;125: 749-56.

7. Halabi AR, Alexander JH, Shaw LK, Lorenz TJ, Liao L, Kong DF, et al. Relation of early saphenous vein graft failure to outcomes following coronary artery bypass surgery. Am J Cardiol. 2005;96:1254-9.

8. Harskamp RE, Lopes RD, Baisden CE, de Winter RJ, Alexander JH. Saphenous vein graft failure after coronary artery bypass surgery: pathophysiology, management, and future directions. Ann Surg. 2013;257:824-33. Review.

9. Samano N, Geijer H, Liden M, Fremes S, Bodin L, Souza D. The no-touch saphenous vein for CABG maintains a patency of 16 years comparable to the left internal thoracic artery: a randomized trial. J Thorac Cardiovasc Surg. 2015; 150:880-8.

10. Verma S, Lovren F, Pan Y, Yanagawa B, Deb S, Karkhanis R, et al. Pedicled no-touch saphenous vein graft harvest limits vascular smooth muscle cell activation: the PATENT saphenous vein graft study. Eur J Cardiothorac Surg. 2014;45:717-25.

11. Allen K, Cheng D, Cohn W, Connolly M, Edgerton J, Falk V, et al. Endoscopic vascular harvest in coronary artery bypass grafting surgery: a consensus statement of the International Society of Minimally Invasive Cardiothoracic Surgery (ISMICS) 2005. Innovations. 2005;1:51-60.

12. Zenati MA, Shroyer AL, Collins JF, Hattler B, Ota T, Almassi GH, et al. Impact of endoscopic versus open saphenous vein harvest technique on late coronary artery bypass grafting patient outcomes in the ROOBY (Randomized On/Off Bypass) Trial. J Thorac Cardiovasc Surg. 2011;141:338-44.

13. van Diepen S, Brennan JM, Hafley GE, Reyes EM, Allen KB, Ferguson TB, et al. Endoscopic harvesting device type and outcomes in patients undergoing coronary artery bypass surgery. Ann Surg. 2014;260:402-8.
14. Williams JB, Peterson ED, Brennan JM, Sedrakyan A, Tavris D, Alexander JH, et al. Association between endoscopic vs open vein-graft harvesting and mortality, wound complications, and cardiovascular events in patients undergoing CABG surgery. JAMA. 2012;308:475-84

15. Zenati MA, Gaziano JM, Collins JF, Biswas K, Gabany JM, Quin JA, et al. Choice of vein-harvest technique for coronary artery bypass grafting: rationale and design of the REGROUP Trial. Clin Cardiol. 2014;37:325-30.

16. Harskamp RE, Alexander JH, Schulte PJ, Brophy CM, Mack MJ, Peterson ED, et al. Vein graft preservation solutions, patency, and outcomes after coronary artery bypass graft surgery: follow-up from the PREVENT IV Randomized Clinical Trial. JAMA Surg. 2014;149:798-805.

17. Sabik JF III. Understanding saphenous vein graft patency. Circulation. 2011;124: 273-5.

18. Goor DA. The importance of the vein graft torsion (addendum to chapter XVIII). In: Goor DA, ed. The Genius of C. Walton Lillehei and the True History of Open Heart Surgery. 1st ed. New York: Vantage Press; 2007:295-7.

19. Bonchek LI, Olinger GN. Technical considerations in saphenous vein bypass grafts to the right coronary artery. Ann Thorac Surg. 1978;25:254-6.

20. Milo S, Massini C, Goor DA. Coronary vein graft marking: a method to prevent graft twisting and length misjudgment. Ann Thorac Surg. 1982;33:200-2.

21. Mehta RH, Ferguson TB, Lopes RD, Hafley GE, Mack MJ, Kouchoukos NT, et al. Saphenous vein grafts with multiple versus single distal targets in patients undergoing coronary artery bypass surgery: one-year graft failure and five-year outcomes from the Project of Ex-Vivo Vein Graft Engineering via Transfection (PREVENT) IV Trial Investigators. Circulation. 2011;124:280-8.

22. Li J, Liu Y, Zheng J, Bai T, Liu Y, Wang X, et al. The patency of sequential and individual vein coronary bypass grafts: a systematic review. Ann Thorac Surg. 2011;92:1292-8.

23. Head SJ, Börgermann J, Osnabrugge RL, Kieser TM, Falk V, Taggart DP, et al. Coronary artery bypass grafting: part 2-optimizing outcomes and future prospects. Eur Heart J. 2013;34:2873-86.

24. Goldman S, Copeland J, Moritz T, Henderson W, Zadina K, Ovitt T, et al. Saphenous vein graft patency one year after coronary artery bypass surgery and effects of antiplatelet therapy. Circulation. 1989;80:1190-7.

25. Sousa-Uva M, Storey R, Huber K, Falk V, Leite-Moreira AF, Amour J, et al; on behalf of ESC Working Group on Cardiovascular Surgery and ESC Working Group on Thrombosis. Expert position paper on the management of antiplatelet therapy in patients undergoing coronary artery bypass graft surgery. Eur Heart J. 2014;35:1510-4.

26. Deo SV, Dunlay SM, Shah IK, Altarabsheh SE, Erwin PJ, Boilson BA, et al. Dual anti-platelet therapy after coronary artery bypass grafting: is there any benefit? A systematic review and meta-analysis. J Card Surg. 2013;28:109-16.

27. Nocerino AG, Achenbach S, Taylor AJ. Meta-analysis of effect of single versus dual antiplatelet therapy on early patency of bypass conduits after coronary artery bypass grafting. Am J Cardiol. 2013;112:1576-9.

28. Kulik A, Voisine P, Mathieu P, Masters RG, Mesana TG, Le May MR, et al. Statin therapy and saphenous vein graft disease after coronary bypass surgery: analysis from the CASCADE Randomized Trial. Ann Thorac Surg. 2011;2:1284-91.

29. van Domburg RT, Meeter K, van Berkel DF, Veldkamp RF, van Herwerden LA, Bogers AJ. Smoking cessation reduces mortality after coronary artery bypass surgery: a 20-year follow-up study. J Am Coll Cardiol. 2000;36:878-83.

30. Meirson T, Orion E, Di Mario C, Webb C, Patel N, Channon KM, et al. Flow patterns in externally stented saphenous vein grafts and development of intimal hyperplasia. J Thorac Cardiovasc Surg. 2015;150:871-9.

31. Taggart DP, Ben Gal Y, Lees B, Patel N, Webb C, Rehman SM, et al. A randomized trial of external stenting for saphenous vein grafts in coronary artery bypass grafting. Ann Thorac Surg. 2015;99:2039-45.

32. Alexander JH, Hafley G, Harrington RA, Peterson ED, Ferguson TB Jr, Lorenz TJ, et al; for the PREVENT IV Investigators. Efficacy and safety of edifoligide, an E2F transcription factor decoy, for prevention of vein graft failure following coronary artery bypass graft surgery: PREVENT IV: a randomized controlled trial. JAMA. 2005;294:2446-54. 